\title{
Heat Assisted Magnetization Reversal on Perpendicular Magnetized Nano-Dot
}

\author{
Nur Aji Wibowo ${ }^{1}$ Cari $^{2}$, and Budi Purnama ${ }^{3}$
}

\begin{abstract}
Heat assisted magnetization reversal on perpendicular magnetized nano-dots has been studied by solved Landau Lifshift-Gilbert equation for magnetic recording application. The heat assisted magnetization reversal scheme has been proven to be effectively reduces threshold field down to $90 \%$. Otherwise, this field doesn't depend on heating time. To understand a read-write information process, cooling time dependence of threshold field has been evaluated. As a result, the threshold field depends on the cooling time and become constant after 300 ps. This result corresponds to data transfer of Hard Disc Drive about $30 \mathrm{~Gb} / \mathrm{s}$.
\end{abstract}

Keywords —magnetic recording, PMA, heat assisted, threshold field, heating time and cooling time

Abstrak-Telah dilakukan evaluasi mode magnetisasi reversal berbantukan panas pada nanodot magnetik beranisotropi tegak lurus dengan menyelesaikan persamaan Landau Lifshift-Gilbert untuk aplikasi perekaman magnetik. Skema magnetisasi reversal berbantukan panas terbukti efektif menurunkan medan threshold hingga 90\%. Namun demikian, medan threshold tidak bergantung pada lamanya pemanasan. Untuk lebih memahami proses baca-tulis informasi, telah dilakukan evaluasi pola hubungan medan threshold terhadap lamanya pendinginan. Dan didapatkan bahwa medan ini bergantung pada lamanya pendinginan dan menjadi konstan setelah 300 ps. Hasil ini terkait dengan kecepatan transfer data pada Hard Disc Drive dalam orde $\mathrm{Gb} / \mathrm{s}$.

Kata Kunci-perekaman magnetik, PMA, berbantukan panas, medan threshold, lama pemanasan, lama pendinginan

\section{INTRODUCTION}

$\mathrm{T}_{\mathrm{s}}$ increase a magnetic disks density, magnetic size must be downsized to nanometer order. When the magnetic size is very small, the room temperature magnetization direction becomes unstable (the recorded magnetic domain relax due to thermal decay over time) $[1,2]$. Large anisotropy magnetic material is required to overcome this thermal fluctuation [3]. Ferromagnetic with large perpendicular magnetic anisotropy (PMA), such as $\mathrm{Co}_{\mathrm{x}} / \mathrm{Pd}_{\mathrm{y}}, \mathrm{Co}_{\mathrm{x}} / \mathrm{Pt}_{\mathrm{y}}, \mathrm{Fe}_{\mathrm{x}} \mathrm{Pt}_{\mathrm{y}}$ etc are considered to be promising candidates for magnetic recording technology. Since 1990, recording densities of magnetic disks have an excellent annual growth up to $100 \%$. In 2005, the commercial magnetic disks density is about 130 $\mathrm{Gbit} / \mathrm{cm}^{2}$. Yet, writing magnetic field becomes insufficient if the media have large anisotropy [1]. A promising method that can be proposed to solve this problem is a Heat Assisted Magnetization Reversal (HAMR). This method was developed since 1999. The main idea of HAMR method is using a heating pulse on nano-dots recording media to reduce the writing magnetic field [4]. By the uses of HAMR method, the densities of magnetic recording exceeding Tbit $/ \mathrm{cm}^{2}$, can be achieved [1]. Therefore, comprehension about HAMR mechanism becomes important to be investigated.

In this HAMR scheme, double pulse i.e. writing field pulse and heating pulse, was adopted. The aim of this paper is to evaluate dependence of threshold field $H_{t h}$ with respect to heating pulse configuration. The threshold field, associated with the writing magnetic

Nur Aji Wibowo is a lecturer in the Physics Department of Satya Wacana Christian University, Indonesia. E-mail: mr_ax_02@yahoo, nurajiwibowo@gmail.com.

Cari is with Student of Postgraduate, Department of Physics, Universitas Sebelas Maret, Surakarta, Indonesia.

Budi Purnama is with Department of Physics, Universitas Sebelas Maret, Surakarta, Indonesia. E-mail: bpurnama@gmail.com. field, is a field which required to aligning magnetization parallel to this field direction.

Reorientation of the magnetization process under an effective field was described by Landau Lifshift Gilbert equation (LLG) [6]:

$\frac{d M^{i}}{d t}=-|\gamma| M^{i} \times H^{i}+\frac{\alpha}{M_{s}} M^{i} \times \frac{d M^{i}}{d t}$

where $M$ is a magnetization, $\alpha$ is a gilbert damping constant $(=0.3), \gamma$ is a gyromagnetic ratio $\left(=1.76 .10^{7}\right.$ $\left.\mathrm{Oe}^{-1} \mathrm{~s}^{-1}\right), H_{\text {eff }}$ is an effective field, $M_{s}$ is a magnetic saturation and $d t$ is an integration time step (=0.12 ps). First term in the right hand side of eq.(1) describes the gyromagnetic precession and the second term is the damping term which describes the motion of the magnetic moment toward the $H_{\text {eff. }}$. The effective field introduced in eq.(1) arises from the following four source [5, 6]: (a) exchange field $H_{e x}$, which appears from interaction between neighboring magnetic moments; (b) magneto-statics field $H_{d}$, that breaks large magnetic particles into smaller magnetic domains, (c) anisotropy field $H_{k}$, which appears from interaction of atomic moments with the crystal surrounding and causes the magnetic moments to be oriented along certain crystallographic direction, (d) at non zero temperatures a random stochastic field $H_{T}$ may be included. This $H_{T}$ will be discussed in numerical method. The $H_{\text {eff }}$ is given as the functional derivative of the energy density $w$ respect to $M$

$H_{\text {eff }}=-\frac{\delta w}{\delta M}$

Interactions are expressed not as particle-particle interaction on the atomic scale, but are contained in macroscopic energy density. The form of the $H_{\text {eff }}$ is understood as the total energy $E$ which is given as the integral functional of the energy density $w$ respect to volume element $d v$

$E=\int w d v$ 
this total energy $E$ has a minimum value for the equilibrium configuration.

If the magnetic size sufficiently small, large energy barrier becomes crucial aspect to ensure thermal stability. Field dependence of energy barrier defined by following equation

$E_{a}=K_{0} V_{0}\left(1-\frac{H}{H_{0}}\right)^{2}$

where parameters $K_{0}$ is material anisotropy, $V_{0}$ is a volume and $H_{0}$ describe the magnet's real structure. Generally, thermal stability of small magnetic media demonstrated by Neel-Brown law

$$
\tau=\tau_{0} \exp \left(\frac{E_{a}}{k_{B} T}\right)
$$

where $E_{a}$ is the activation energy associated with the energy barrier $\Delta E, k_{B}$ is a boltzman constant, $T$ is a temperature and value of $\tau_{0} \approx 10^{-10} \mathrm{~s}$. equation (5) can also be expressed as:

$$
E_{a}=k_{B} T \ln \left(\frac{\tau}{\tau_{0}}\right)
$$

when we assumed loss data stored at Hard Disc Drive (HDD) for 10 years, $\tau \approx 10$ years $\left(10^{8} \mathrm{~s}\right)$, so the corresponding $\Delta E$ for insured thermal stability at room temperature should be much larger than $40 k_{b} T[2,6]$.

\section{METHOD}

In consideration a PMA magnetized nano-dots as a magnetic recording media, reversal mode of HAMR evaluated by solve the LLG equation. An approximation of thermal fluctuation effect occurring during magnetization is taken into account by involving randomly oriented effective fields with zero mean value, $\left\langle\mathrm{H}_{\text {eff }}^{\prime}(t)\right\rangle=0$. Whereas, strength of the random field due to the thermal fluctuation effect is calculated by using a fluctuation dissipation theorem [7]:

$\sigma=\sqrt{\frac{2 k_{B} T \alpha}{\gamma V M_{s} \Delta t}}$

where $\sigma$ is a fluctuation factor, $V$ is a volume of cell memory $\left(=50 \times 50 \times 20 \mathrm{~nm}^{3}\right)$ and $\Delta t$ is time increment. To evaluate heat effects with respect to threshold field and initial condition of magnetization, calculation of magnetization probability aligning to field direction was performed for 20 different series of random number. This probability reaches to 1 at threshold field $H_{t h}$. Temperature dependence of exchange stiffness and anisotropy constant which are related with the thermally reduced magnetization was assumed as [5]:

$$
\begin{aligned}
& A(T)=A^{(0)}\left(\frac{M_{S}(T)}{M_{S}(0)}\right)^{2} \\
& K_{\perp}(T)=K_{\perp}^{(0)}\left(\frac{M_{S}(T)}{M_{S}(0)}\right)^{2}
\end{aligned}
$$

where $A$ is a exchange stiffness constant and $K_{\perp}$ is a perpendicular anisotropy constant. While the temperature dependence of magnetization defined by following equation [8].

$$
M_{S}(T)=M_{S}^{(0)}\left(1-\frac{T}{T_{C}}\right)^{0,5}
$$

Value of this physical parameters used in the simulation are exchange stiffness constant $A=1.10^{7}$ $\mathrm{erg} / \mathrm{cm}$, anisotropy constant $K_{\perp}=8.10^{4} \mathrm{erg} / \mathrm{cc}, 4 \pi M_{S}=$ $2.1 \mathrm{kG}$ which corresponds to energy barrier $\approx 150 k_{b} T$ at room temperature and Currie temperature $=373 \mathrm{~K}$.

Figure 1 illustrates the HAMR scheme in this paper. A bias field $H_{w}$, which pulse width is $4.75 \mathrm{~ns}$, was applied. And a heating pulse $T_{w}$, which its pulse width is $2.5 \mathrm{~ns}$, was applied after $1 \mathrm{~ns}$.

\section{RESULTS AND DISCUSSION}

\section{A. Types Modes of Magnetization}

In order to know deeply a heat fluctuation effect in Heat Assisted Magnetization Reversal mode, a change of energy barrier $\Delta E$ because of this heat fluctuation effect is evaluated for four different models. Physical properties which used in this simulation are $K_{\perp}=3.10^{5}$ $\mathrm{erg} / \mathrm{cc}$ and $4 \pi M_{S}=2.1 \mathrm{kG}$. Model $\mathrm{A}$ is the magnetization process by excluding the heat fluctuation effect in a configuration of initial magnetization and the $H_{\text {eff. }}$. Model $\mathrm{B}$ is the magnetization process by including the heat fluctuation effect in the configuration of initial magnetization. Model $\mathrm{C}$ is the magnetization process by including the heat fluctuation effect in the $H_{\text {eff. }}$ Finally, model $\mathrm{D}$ is the magnetization process by including the heat fluctuation effect in the configuration of initial magnetization and the $H_{\text {eff }}$. Furthermore, the magnetization reversal mechanism is evaluated by observe a visualization of micrograph of magnetization. In this paper, $\Delta E$ is defined as a difference of a value between a minimum and maximum level energy as shown in Figure 1. This $\Delta E$ separates the two of difference minimum state. In the magnetic recording application, the two of difference minimum state associated with an opposite direction of magnetization (in the $H_{w}$ direction and the oppositely). And a switching field $H_{s w t}$ is defined as a minimum $H_{w}$ which is required to overcome the $\Delta E$ so that the magnetization reverse into $H_{w}$ direction.

Figure 2 illustrates an energy barrier shape from four different models. From Figure 1(a-b) observed that a characteristic of $\Delta E$ is symmetric and smooth. Whereas a decreasing of the minimum level energy and the $\Delta E$ with an increasing of temperature $T$ as shown at Figure 1(b-d). The different result was obtained if the fluctuation of $H_{\text {eff }}$ include in the calculation. Figure 1(c-d) shows that under the fluctuation of $H_{e f f}$ effect, the characteristic of $\Delta E$ becomes asymmetric and ripple. And the $\Delta E$ vanish when $T$ close to $T_{c}$ so that the material lose its magnetism.

From Figure 2, the $T / T_{c}$ dependence of the $\Delta E$ can be plotted. The decreasing of the $\Delta E$ to the increasing of the $T / T_{c}$ observed from Figure 3. As shown from the figure that the $H_{\text {eff }}$ fluctuation caused the fluctuating of $\Delta E$. For models $\mathrm{C}$ and $\mathrm{D}$, at $T / T c \approx 99 \%$, the $\Delta E$ can still be realized with the value larger than $100 k_{B} \mathrm{~T}$. It means that the magnetization reversal possible to be realized at high temperature.

The magnetization reversal mechanism of each model can be observed from Figure 4. Figure 4(a) represents the reversal mechanism of state which excluding the heat fluctuation effect. Observed from the figure, at (i), $t=0$ ns, the value of $M_{\text {easy }} / M_{\text {sat }}$ is equal to zero. At this time, the magnetization saturated in the opposite direction of $H_{w}$. Then, throughout a present of $H_{w}$ in a negative direction which the value rise linearly from 0 to $2 \mathrm{~T}$, the 
value of $M_{\text {easy }} / M_{\text {sat }}$ down towards negative value. At (ii), $t=0.83 \mathrm{~ns}$, the value of $M_{\text {easy }} / M_{\text {sat }}$ is equal to 0.1 . And at (iii), $t=0.85 \mathrm{~ns}$, the value of $M_{\text {easy }} / M_{\text {sat }}$ is equal to -0.4 . In this interval, the magnetization gradually turned towards $H_{w}$ direction. After $0.85 \mathrm{~ns}$, the magnetization is saturated in the direction of $H_{w}$ which corresponds to the value of $M_{\text {easy }} / M_{\text {sat }}$ equal to - 1 .

Figure $4(\mathrm{c}-\mathrm{d})$ describes that the fluctuation of $H_{\text {eff }}$ caused the value of $M_{\text {easy }} / M_{\text {sat }}$ drop and become $\approx 0$ at $T / T_{c} \approx 100 \%$. It means that at that time, randomly magnetized state be realized. In this paper, $t_{\text {reversal }}$ is defined as a time which is required to reverse the magnetization so that the magnetization saturate in the $H_{w}$ direction. Reflected from the Figure 4(b-d) that the increasing of temperature shortening the $t_{\text {reversal }}$. From this figure, the $T / T_{c}$ dependence of the $t_{\text {reversal }}$ can be plotted. The shortening of $t_{\text {reversal }}$ with respect to the increasing of the $T / T_{c}$ observed from Figure 5. By comparing the $t_{\text {reversal }}$ at $\mathrm{B}, \mathrm{C}$ and $\mathrm{D}$, observed that the presence of the $H_{\text {eff }}$ fluctuation shorten the $t_{\text {reversal }}$.

The magnetization reversal magnetization also can be reflected on micrograph of magnetization as shown in Figure 6. Which is the magnetization parallel to the $H_{w}$ direction shown by black color, and white color shows the opposite direction, vice versa. This figure describes that for models $\mathrm{A}$ and $\mathrm{B}$, the magnetization reversal mechanism begins with a smooth domain wall nucleation from a center. This domain wall expands until a single domain configuration in the $H_{w}$ direction has been realized. In the other side, for models $\mathrm{C}$ and $\mathrm{D}$, the magnetization reversal mechanism begins with the domain wall nucleation from an edge. This domain wall expands until a single domain configuration in the $H_{w}$ direction has been realized.

\section{B. Heat Assisted Magnetization Reversal}

Figure 7 represents the HAMR mechanism under a bias field $H_{w}$. Observed from the figure that for $\mathrm{t}<1 \mathrm{~ns}$, the magnetization constant. Yet, when the heat is applied ( $\mathrm{t} \geq 1 \mathrm{~ns}$ ), the magnetization change quickly and disordered when the heat approximate to Curie point. This randomly magnetized state shown with the value of $M_{\text {eas }} / M_{\text {sat }}$ about 0 . After $3 \mathrm{~ns}$, the heat is lowered to room temperature. And the magnetization aligning to $H_{w}$ direction at room temperature, which called reversal state. At this state, read and write information is going on and then the information saved at room temperature.

The heat assisted magnetization reversal mechanism also can be reflected on micro-magnetic-graph of magnetization as shown in Figure 8, which is the magnetization parallel to the $H_{w}$ direction shown by white color, and black color shows the opposite direction, vice versa. Observed from micro-magneticgraph, for $t<2 \mathrm{~ns}$, the magnetization dominated by multi domain configuration. During heating process, $2<t<3$ $\mathrm{ns}$, the random magnetization realized. Whereas for cooling writing process, $t>3 \mathrm{~ns}$, the magnetization reversal mechanism starts with a domain wall nucleation and continued by domain wall annihilation so that single domain to the $H_{w}$ direction realized.

Figure 9 exhibits a decreasing of $H_{t h}$ as a function of a writing temperature to Curie temperature ratio $\left(T_{w} / T_{c}\right)$. At $T_{w} / T_{c}=80 \%, 2300$ Oe of $H_{t h}$ is required to aligning the magnetization in the $H_{w}$ direction. However, at $T_{w} / T_{c}$ $\approx 99 \%$, only 250 Oe of $H_{t h}$ is needed. This HAMR scheme proven to be effectively to reduce the $H_{t h}$ down to $90 \%(=(2300-250) \times 100 \% / 2300)$. The decreased of $H_{t h}$ can be attributed to a reduction of $\Delta E$ during heating process. The reduced of the $\Delta E$ mechanism due to heat activation is illustrated at Figure 10.

Although a heating scheme has been proven to be effectively reduces the $H_{t h}$, in the other hand, this field doesn't depend on heating time $t_{h}$ as shown at Figure 11(a). This field is constant around $250-300$ Oe in 800 ps. This $t_{h}$ independence of $H_{t h}$ shows that the randomly magnetized state doesn't change with the vary of $t_{h}$. However, it is possible to shorten the $t_{h}$ in femto seconds order.

In order to understand transfer data to or from HDD process, the cooling time $t_{w}$ dependences of $H_{t h}$ has been evaluated. Observed from Figure 11(b), the $H_{t h}$ decreases with an increasing of $t_{w}$ and becomes constant after 300 ps. The $H_{t h}$ reduced about $45 \%(=(550-300) \times 100 \% / 550)$ from 550 Oe at $t_{w}=0.019$ ps to 300 Oe at $t_{w}=300$ ps. This field becomes stable around 250-300 Oe after 300 ps. It can be related to static and dynamic magnetization mechanism in the magnetization reversal process. This result corresponds to data transfer of HDD about $\mathrm{Gb} / \mathrm{s}$.

\section{CONCLUSION}

The Heat assisted magnetization reversal on perpendicular magnetized nano-dots has been studied by solved Landau Lifshift-Gilbert equation for magnetic recording application. The heat assisted magnetization reversal scheme has been proven to be effectively reduces threshold field down to $90 \%$. Otherwise, this field doesn't depend on heating time. To understand a read-write information process, cooling time dependence of threshold field has been evaluated. As a result, the threshold field depends on the cooling time and become constant after 300 ps. This result corresponds to data transfer of hard disc drive about $\mathrm{Gb} / \mathrm{s}$.

\section{REFERENCES}

[1] Koji Matsumoto, Akhihiro Inomata, and Shin-ya Hasigawa, "Thermally assisted magnetic revording", FUJITSU Sci. Tech. J.,Vol. 42, pp. 158. 2006.

[2] Ralph Skomski, "Role of thermodynamic fluctuation in magnetic recording", Journal of Applied Physics, Vol. 101. No. 09B104 2007.

[3] Keita Waseda, Ryosuke Doi, Budi Purnama, Satoru Yoshimura, Yukio Nozaki and Kimihide Matsuyama, "Heat-assisted magnetization reversal using pulsed laser irradiation in patterned magnetic thin film with perpendicular anisotropy", IEEE Transactions on Magnetics, Vol . 44, No.11, pp. 2483-2486, 2008.

[4] R.C. Sousa, C. Prejbeanu, "Non-volatile Magnetic Random Access Memories (MRAM)", C.R. Physique, Vol. 6. No. 9, pp. 1013-1021, 2005.

[5] Purnama, Budi, "Thermally assisted magnetization reversal in perpendicularly magnetized thin film", Doctoral Thesis, Electronics Department Graduated School of Information Science and Eectrical Engineering, Kyushu University, Japan, 2009.

[6] T. Schrelf, J. Fidler, D. Suess, W. Scholz, and V. Tsiantos, "Handbook of magnetic materials: micro magnetic simulation of dynamic and thermal effects", Tsinghua University Press, 2006, pp.129-130.

[7] K.J. Lee and T.D. Lee, "Effect of the thermal fluctuation on switching field of deep submicron sized soft magnetic thin film", Journal of Applied Physics, Vol. 91, No. 10, pp. 7706-7708, 2002.

[8] Y. Nosaki, Y. Isowaki, A. Hashimoto, B. Purnama and K. Matsuyama, "Numerical analysis of thermally assisted 
magnetization reversal in rectangular MRAM cell consisted of exchange coupled bilayer", J. Magn. Soc. Japan., Vol. 30, pp. 574-577, 2006.

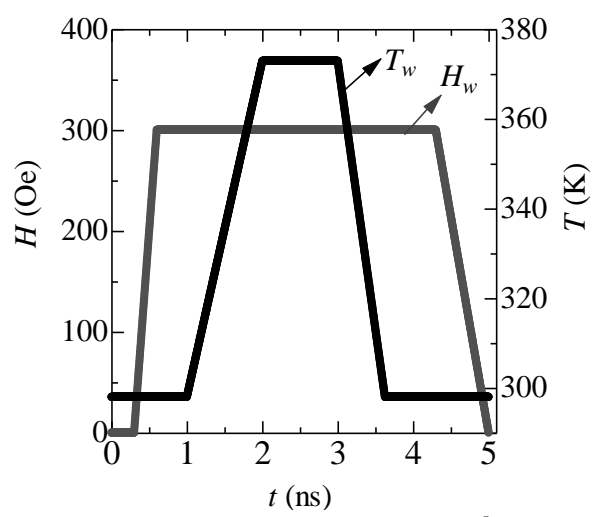

Figure 1. HAMR scheme which calculated for $K_{\perp}=3.10^{5} \mathrm{erg} / \mathrm{cc}, 4 \pi M_{S}=2.1 \mathrm{kG}$

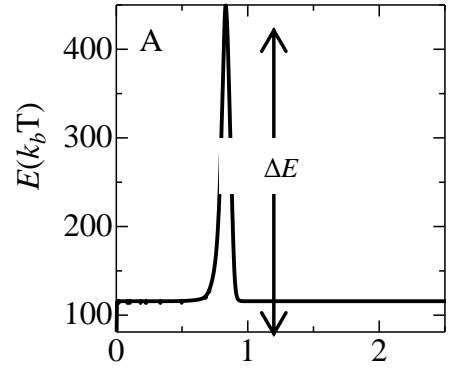

$t$ (ns)

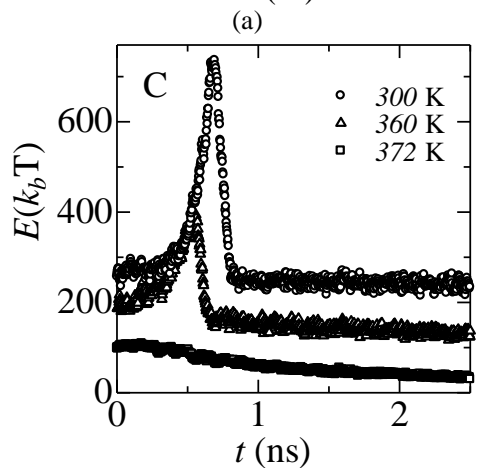

(c)

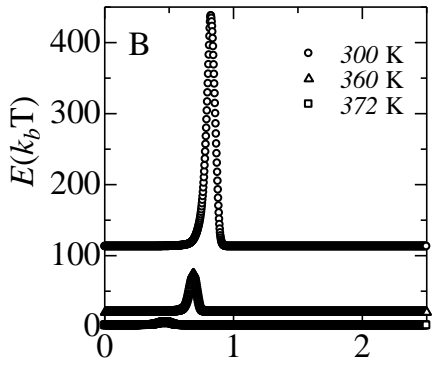

$t$ (ns)

(b)

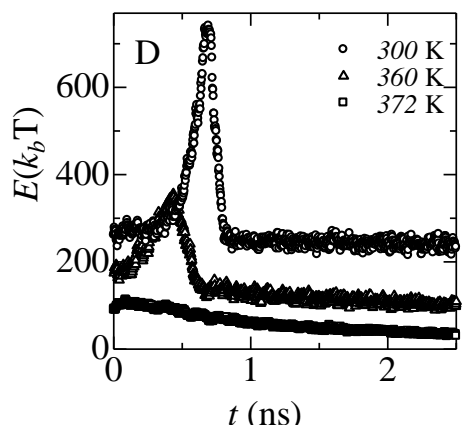

(d)

Figure 2. The energy barrier $\Delta E$ shape from four different models (a, b, c, and d) calculated for $K_{\perp}=3.10^{5} \mathrm{erg} / \mathrm{cc}, 4 \pi M_{S}=2.1 \mathrm{kG}$. (a) the magnetization process by excluding the heat fluctuation effect in a configuration of initial magnetization and the $H_{e f f}$, (b) the magnetization process by including the heat fluctuation effect in the configuration of initial magnetization, (c) the magnetization process by including the heat fluctuation effect in the $H_{\text {eff, }}$ (d) the magnetization process by including the heat fluctuation effect in the configuration of initial magnetization and the $H_{\text {eff }}$

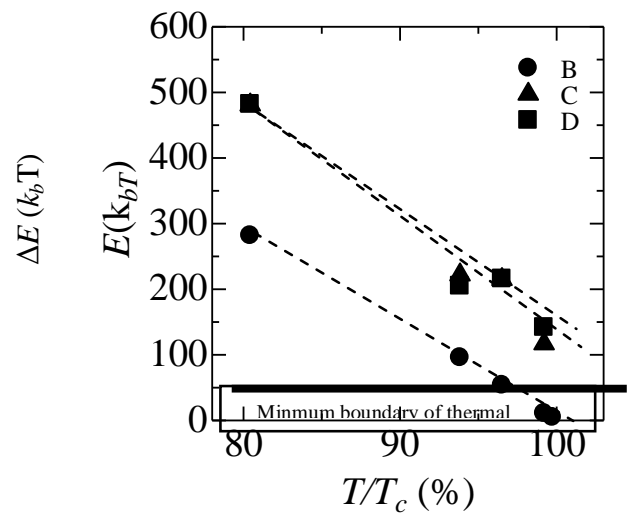

Figure 3. The decreasing of the $\Delta E$ to the increasing of the $T / T_{c}$ calculated for $K_{\perp}=3.10^{5} \mathrm{erg} / \mathrm{cc}, 4 \pi M_{S}=2.1 \mathrm{kG}$ 


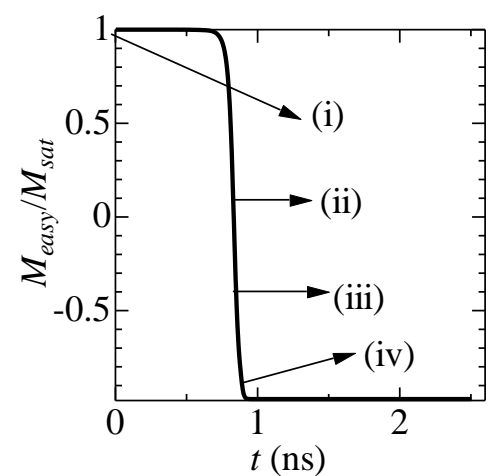

(a)

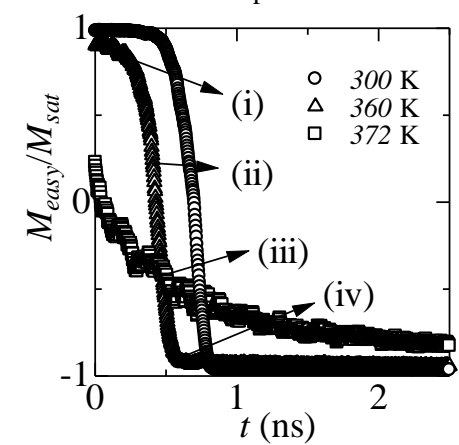

(c)

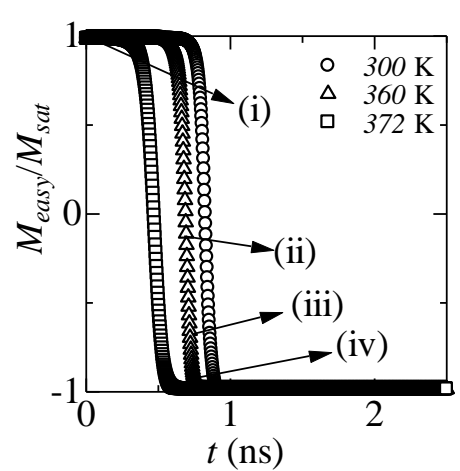

(b)

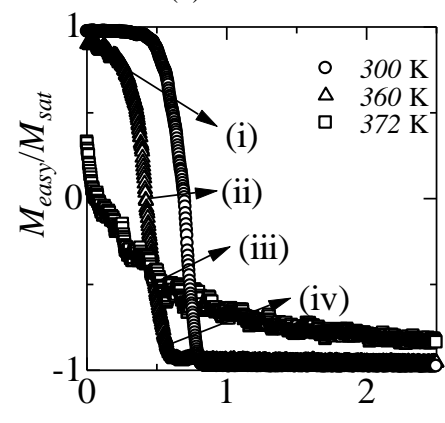

(d)

$t(\mathrm{~ns})$

Figure 4. The magnetization reversal mechanism from four different models (a, b, c, and d) calculated for $K_{\perp}=3.10^{5} \mathrm{erg} / \mathrm{cc}, 4 \pi M_{S}=2.1 \mathrm{kG}$

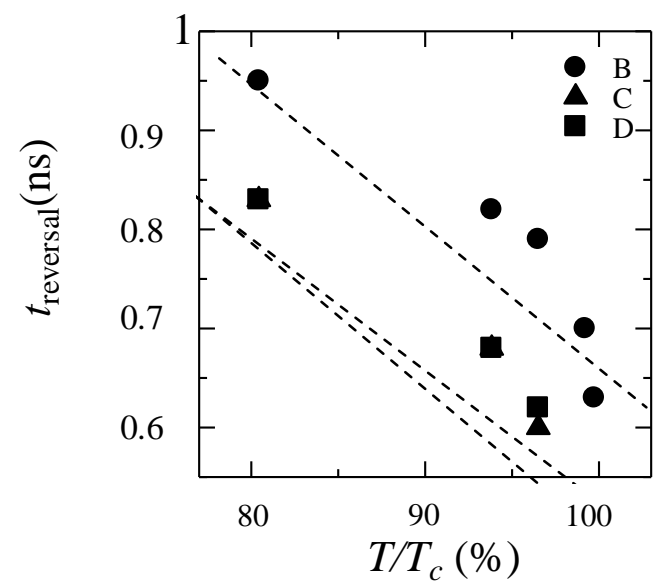

Figure 5. The $T / T_{c}$ dependence of the $t_{\text {reversal }}$ calculated for $K_{\perp}=3.10^{5} \mathrm{erg} / \mathrm{cc}, 4 \pi M_{S}=2.1 \mathrm{kG}$ 


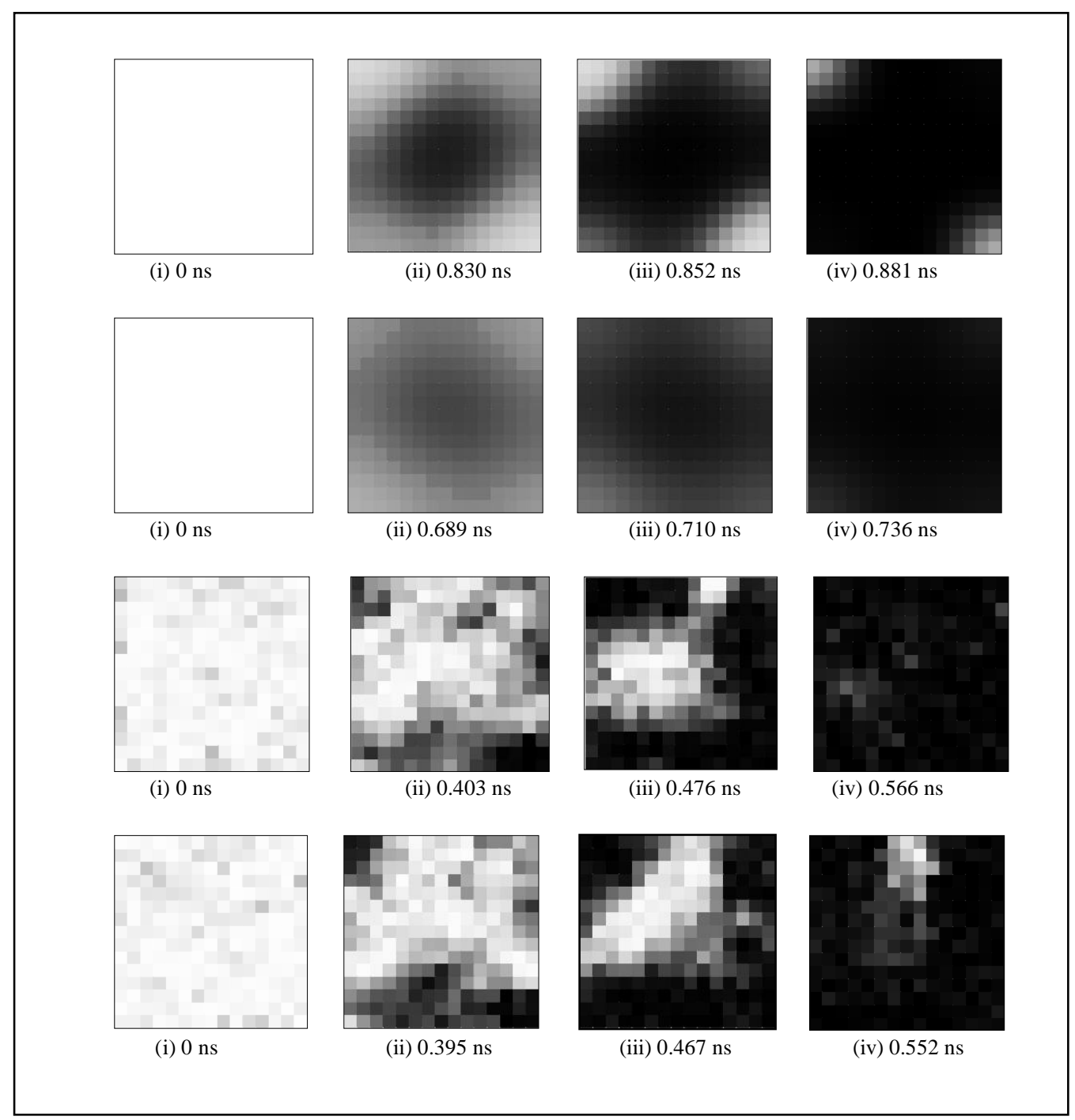

Figure 6. The micromagneticgraph of the magnetization reversal mechanism from four different models (A, B, C and D) calculated for $K_{\perp}=3.10^{5}$ $\mathrm{erg} / \mathrm{cc}, 4 \pi M_{S}=2.1 \mathrm{kG}$. Which is the magnetization parallel to the $H_{w}$ direction shown by black color, and white color shows the opposite direction, vice versa

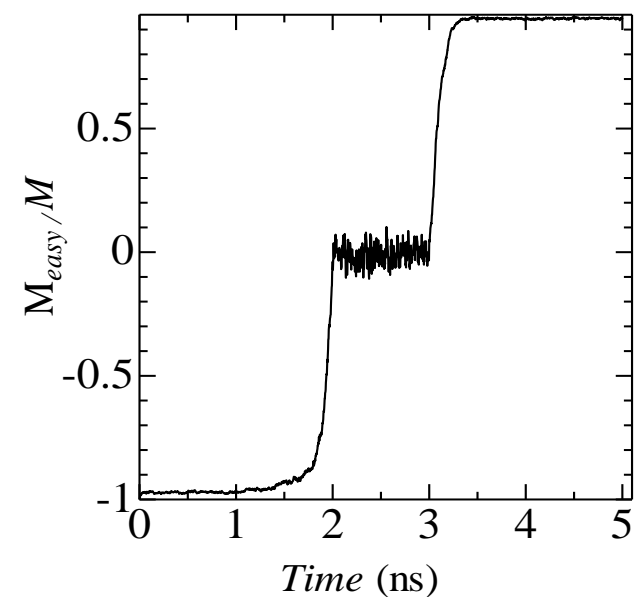

Figure 7. Magnetization reversal process which calculated for $K_{\perp}=3.10^{5} \mathrm{erg} / \mathrm{cc}, 4 \pi M_{S}=2.1 \mathrm{kG}$ and a heating pulse $T_{w}=372.3 \mathrm{~K}$ 


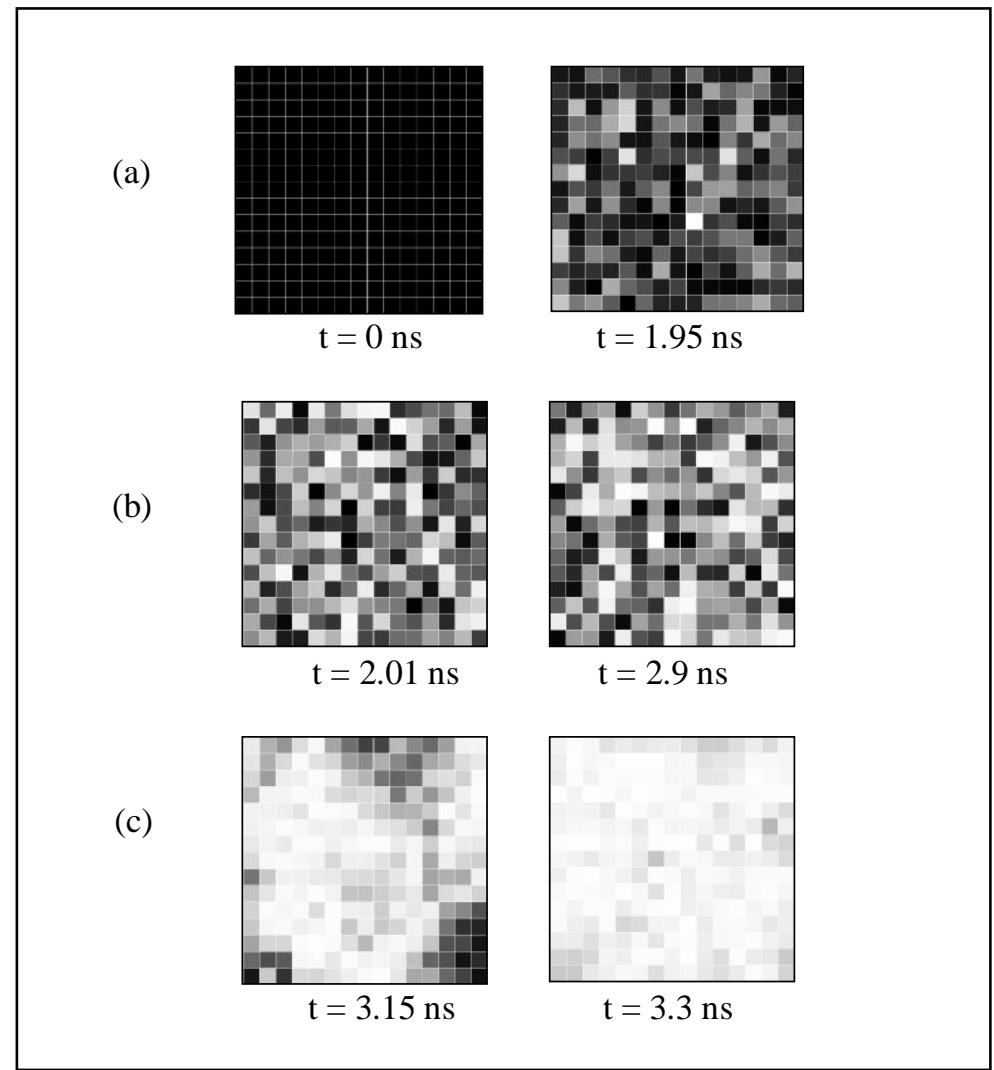

Figure 8. Micromagneticgraph of HAMR which calculated for $K_{\perp}=8.10^{4} \mathrm{erg} / \mathrm{cc}, 4 \pi M_{\mathrm{S}}=1.5 \mathrm{kG}$ and a heating pulse $T_{w}=372.3 \mathrm{~K}$. (a) before heating applied, $\mathrm{t}<2 \mathrm{~ns}$, (b) during heating process, $2<\mathrm{t}<3 \mathrm{~ns}$ and (c) cooling writing/after heating process, $\mathrm{t}>3 \mathrm{~ns}$. Which is the magnetization parallel to the $H_{w}$ direction shown by white color, and black color shows the opposite direction, vice versa

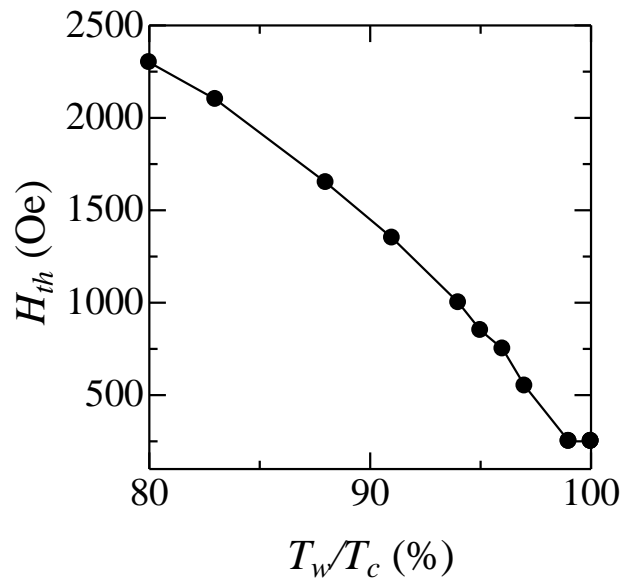

Figure 9. Reduces of threshold field $H_{t h}$ with respect to rising of $T / T_{c}$ which calculated for $K_{\perp}=3.10^{5} \mathrm{erg} / \mathrm{cc}$ and $4 \pi M_{S}=2.1 \mathrm{kG}$

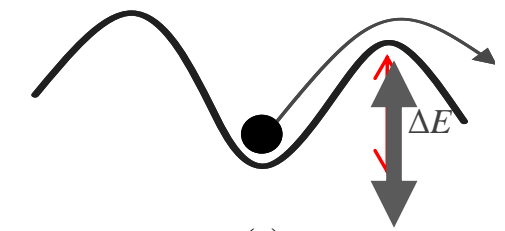

(a)

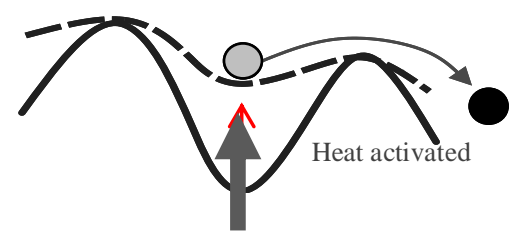

(b)

Figure 10. The reduced of the barrier $\Delta E$ mechanism caused by heating effect scheme: (a) Initial energy barrier, (b) energy barrier during heating process 

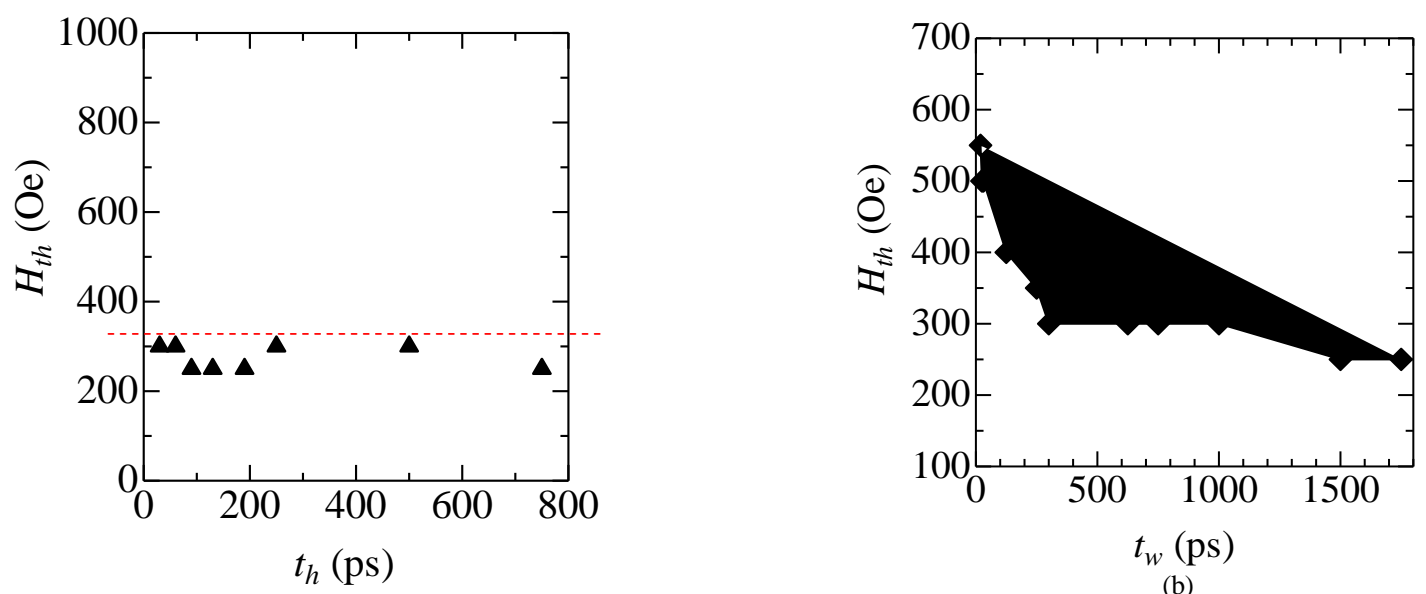

(a)

(b)

Figure 11. (a) Independences and (b) dependence of $H_{t h}$ with respect to heating time $t_{h}$ which calculated for $K_{\perp}=3.10^{5} \mathrm{erg} / \mathrm{cc}, 4 \pi M_{S}=2.1 \mathrm{kG}$ and $T_{w}=372.3 \mathrm{~K}$ 